\title{
Significant association between TAP2 polymorphisms and rheumatoid arthritis: a meta-analysis
}

Dongjun Dai ${ }^{1 \dagger}$, Yong Chen ${ }^{2 \dagger}$, Ping Ru' ${ }^{1}$ Xingyu Zhou ${ }^{1}$, Jianmin Tao ${ }^{1}$, Huadan Ye ${ }^{1}$, Qingxiao Hong ${ }^{1}$, Linlin Tang ${ }^{1}$,

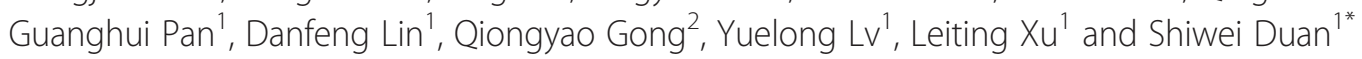

\begin{abstract}
Background: Rheumatoid arthritis (RA) is a severe chronic immune mediated inflammatory disease that has been shown to be associated with human leukocyte antigen (HLA) loci. The transporter associated with antigen processing 2 (TAP2) has been identified to play an important role in the HLA-associated diseases and immune response. The goal of our meta-analysis was to summarize the contribution of TAP2 polymorphisms to the risk of RA.
\end{abstract}

Methods: Meta-analyses were performed between RA and 3 TAP2 coding polymorphisms that comprised TAP2-379lle > Val (rs1800454), TAP2-565Ala > Thr (rs2228396) and TAP2-665Thr > Ala (rs241447). The meta-analyses were involved with 9 studies (24 individual studies) among 973 cases and 965 controls.

Results: Meta-analyses showed that TAP2-379lle allele was significantly associated with an increased risk of RA $(p=0.0002$, odds ratio $(\mathrm{OR})=1.44,95 \%$ confidence interval $(C \mathrm{l})=1.18-1.74)$. This association was further shown only in the dominant model $(p=0.006, \mathrm{OR}=1.59,95 \% \mathrm{Cl}=1.14-2.22)$. Subgroup analyses by ethnicity revealed that the association of TAP2-379lle was significant in Asians ( $p=0.03, \mathrm{OR}=1.38,95 \% \mathrm{Cl}=1.04-1.83$ ). In addition, another significant association of TAP2-565Thr allele with RA was observed in Europeans ( $p=0.002, \mathrm{OR}=1.62,95 \% \mathrm{Cl}=1.20-2.20$ ).

Conclusions: Our meta-analyses suggested that TAP2-379lle allele was significantly associated with a 59\% increased risk in the dominant effect model. Subgroup analyses by ethnicity showed that TAP2-379-lle increased the risk of RA by 38\% in Asians and TAP2-565Thr increased the risk of RA by 38\% in Europeans.

Virtual Slides: The virtual slide(s) for this article can be found here: http://www.diagnosticpathology.diagnomx.eu/vs/ 2097080313124700

Keywords: Rheumatoid arthritis, Polymorphism, Meta-analysis, TAP2, Ethnicity

\section{Background}

Rheumatoid arthritis (RA) is a common immune-mediated chronic inflammatory disease [1]. Severe clinical symptoms of RA comprise bone lose [2] and heart diseases [3] that can make a huge destruction to human body. RA is a complex disease caused by both genetic and environmental factors. Twin studies estimated a large heritability $(60 \%)$ in RA [4]. Family-based studies also demonstrated that genetic factors played a more important role in the development of RA than environmental factors $[5,6]$.

\footnotetext{
* Correspondence: duanshiwei@nbu.edu.cn

${ }^{\dagger}$ Equal contributors

'Zhejiang Provincial Key Laboratory of Pathophysiology, School of Medicine, Ningbo University, Ningbo, Zhejiang 315211, China

Full list of author information is available at the end of the article
}

Consistent association was found between human leukocyte antigen (HLA) loci and RA [7]. The transporter associated with antigen processing 2 (TAP2) gene encodes transporter 2, ATP-binding cassette, sub-family B (MDR/ TAP) that is a major histocompatibility complex (MHC) gene located between HLA-DP and HLA-DQ [8]. TAP2 delivers antigenic peptides to the endoplasmic reticulum of HLA class I molecular [9], especially in selecting the size of peptides [10]. TAP2 has been shown to play an important role in the HLA-associated diseases and immune response [11].

TAP2 polymorphisms have been tested for their association with the occurrence and development of RA [12-23]. Among them, Ile379Val, Ala565Thr and Thr665Ala are 
most often studied [14-23]. Altogether there were 10 case-control studies for the TAP2 polymorphisms with RA, yielding only 2 significant results (Table 1 ). We suspected that a lack of power in the previous studies with moderate sample size might influence the reliability of the results [24]. Meta-analysis is often used to enhance statistical power and thus is likely to produce a more convincing conclusion [25]. Here we performed a set of meta-analyses of the three polymorphisms by pooling up the data from individual association study [25]. Our research is likely to provide a better evaluation of the contribution of TAP2 polymorphisms to the risk of RA.

\section{Methods}

We collected studies that examined the associations of TAP2 polymorphisms with RA in September of 2013 by searching the online databases (PubMed, WanFang, WeiPu and $\mathrm{CNKI}$ ) without time and language restriction, using the keywords "rheumatoid arthritis TAP2 association" and "rheumatoid arthritis TAP2 polymorphism". The obtained
Table 2 Nomenclature of TAP2 haplotypes

\begin{tabular}{|c|c|c|c|c|c|c|}
\hline \multirow[t]{2}{*}{ TAP2 } & \multicolumn{2}{|c|}{ TAP2-379 } & \multicolumn{2}{|c|}{ TAP2-565 } & \multicolumn{2}{|c|}{ TAP2-665 } \\
\hline & GTA & $\overline{\text { ATA }}$ & GTA & $\overline{\text { ATA }}$ & $\overline{\text { GTA }}$ & $\overline{\text { ATA }}$ \\
\hline A & Val & & Ala & & Thr & \\
\hline B & Val & & Ala & & & Ala \\
\hline C & & Ile & Ala & & Thr & \\
\hline$D$ & & Ile & & Thr & Thr & \\
\hline E & Val & & & Thr & Thr & \\
\hline$F$ & Val & & Ala & & Thr & \\
\hline G & & Ile & Ala & & & Ala \\
\hline $\mathrm{H}$ & & lle & & Thr & & Ala \\
\hline
\end{tabular}

studies would be included in our meta-analyses if they met the following criteria: (1) It was an original case-control study with an assessment of the association of TAP2 with RA in humans; (2) It contains sufficient information to infer the odds ratios (ORs) and 95\% confidence intervals

Table 1 Characteristics of the case-control studies in the current meta-analyses

\begin{tabular}{|c|c|c|c|c|c|c|c|c|c|c|c|}
\hline Gene locus & First author & Year & Country & Ethnicity & $\begin{array}{l}\text { Genotyping } \\
\text { method }\end{array}$ & $\begin{array}{l}\text { Cases/ } \\
\text { controls }\end{array}$ & Control source & HWE & Result* & Power & MAF \\
\hline \multirow[t]{8}{*}{ TAP2-379 } & B. P. Wordsworth [14] & 1993 & Britain & Europeans & ARMS-PCR & $60 / 117$ & Population & NA & NS & 0.101 & 0.167 \\
\hline & Sara Marsal [15] & 1994 & America & Europeans & ARMS-PCR & $185 / 48$ & Population & NA & NS & 0.086 & 0.177 \\
\hline & M.C. Hillarby [16] & 1996 & Britain & Europeans & ARMS-PCR & $89 / 64$ & Population & NA & S & 0.091 & 0.172 \\
\hline & F. Takeuchi [17] & 1997 & Japan & Asians & PCR-RFLP & $92 / 95$ & Population & NA & NS & 0.095 & 0.132 \\
\hline & J Vinasco [18] & 1998 & Spain & Europeans & PCR-RFLP & $50 / 55$ & Population & NA & NS & 0.072 & 0.109 \\
\hline & Sasijit Vejbaesya [19] & 2000 & Thailand & Asians & ARMS-PCR & $82 / 100$ & Population & Yes & NS & 0.115 & 0.220 \\
\hline & S.-L. Zhang [20] & 2002 & France & Europeans & ARMS-PCR & 138/100 & Population & Yes & NS & 0.098 & 0.120 \\
\hline & Min-Chien Yu [21] & 2004 & China & Asians & PCR-RFLP & $100 / 99$ & Population & Yes & NS & 0.124 & 0.237 \\
\hline \multirow[t]{8}{*}{ TAP2-565 } & B. P. Wordsworth [14] & 1993 & Britain & Europeans & ARMS-PCR & $60 / 117$ & Population & NA & NS & 0.094 & 0.132 \\
\hline & Sara Marsal [15] & 1994 & America & Europeans & ARMS-PCR & $185 / 48$ & Population & NA & NS & 0.081 & 0.156 \\
\hline & M.C. Hillarby [16] & 1996 & Britain & Europeans & ARMS-PCR & $89 / 64$ & Population & NA & NS & 0.086 & 0.148 \\
\hline & F. Takeuchi [17] & 1997 & Japan & Asians & PCR-RFLP & $92 / 95$ & Population & NA & S & 0.09 & 0.116 \\
\hline & J Vinasco [18] & 1998 & Spain & Europeans & PCR-RFLP & $50 / 55$ & Population & NA & NS & 0.059 & 0.036 \\
\hline & S.-L. Zhang [20] & 2002 & France & Europeans & ARMS-PCR & $138 / 100$ & Population & Yes & S & 0.078 & 0.070 \\
\hline & Min-Chien Yu [21] & 2004 & China & Asians & PCR-RFLP & $100 / 99$ & Population & Yes & NS & 0.086 & 0.096 \\
\hline & Yu L [22] & 2013 & China & Asians & PCR-RFLP & $177 / 288$ & Population & Yes & NS & 0.169 & 0.142 \\
\hline \multirow[t]{8}{*}{ TAP2-665 } & B. P. Wordsworth [14] & 1993 & Britain & Europeans & ARMS-PCR & $60 / 117$ & Population & NA & NS & 0.115 & 0.248 \\
\hline & Sara Marsal [15] & 1994 & America & Europeans & ARMS-PCR & $185 / 48$ & Population & NA & NS & 0.084 & 0.167 \\
\hline & M.C. Hillarby [16] & 1996 & Britain & Europeans & ARMS-PCR & $89 / 64$ & Population & NA & NS & 0.119 & 0.375 \\
\hline & F. Takeuchi [17] & 1997 & Japan & Asians & PCR-RFLP & $92 / 95$ & Population & NA & NS & 0.136 & 0.347 \\
\hline & J Vinasco [18] & 1998 & Spain & Europeans & PCR-RFLP & $50 / 55$ & Population & NA & NS & 0.091 & 0.264 \\
\hline & Juha Tuokko [23] & 1998 & Finland & Europeans & PCR-RFLP & $40 / 60$ & Population & No & NS & 0.095 & 0.350 \\
\hline & S.-L. Zhang [20] & 2002 & France & European & ARMS-PCR & 138/100 & Population & Yes & NS & 0.148 & 0.300 \\
\hline & Min-Chien Yu [21] & 2004 & China & Asians & PCR-RFLP & $100 / 99$ & Population & Yes & NS & 0.147 & $0.601^{*}$ \\
\hline
\end{tabular}

ARMS-PCR: Amplification refractory mutation system; PCR-RFLP: Polymerase Chain Reaction -Restriction Fragment Length Polymorphism; HWE. Hardy-Weinberg equilibrium; Result*, The association between IL1B gene and PD; NS, No significant; S, Significant; NA: Not applicable; *The reference allele is TAP2-665Ala. 


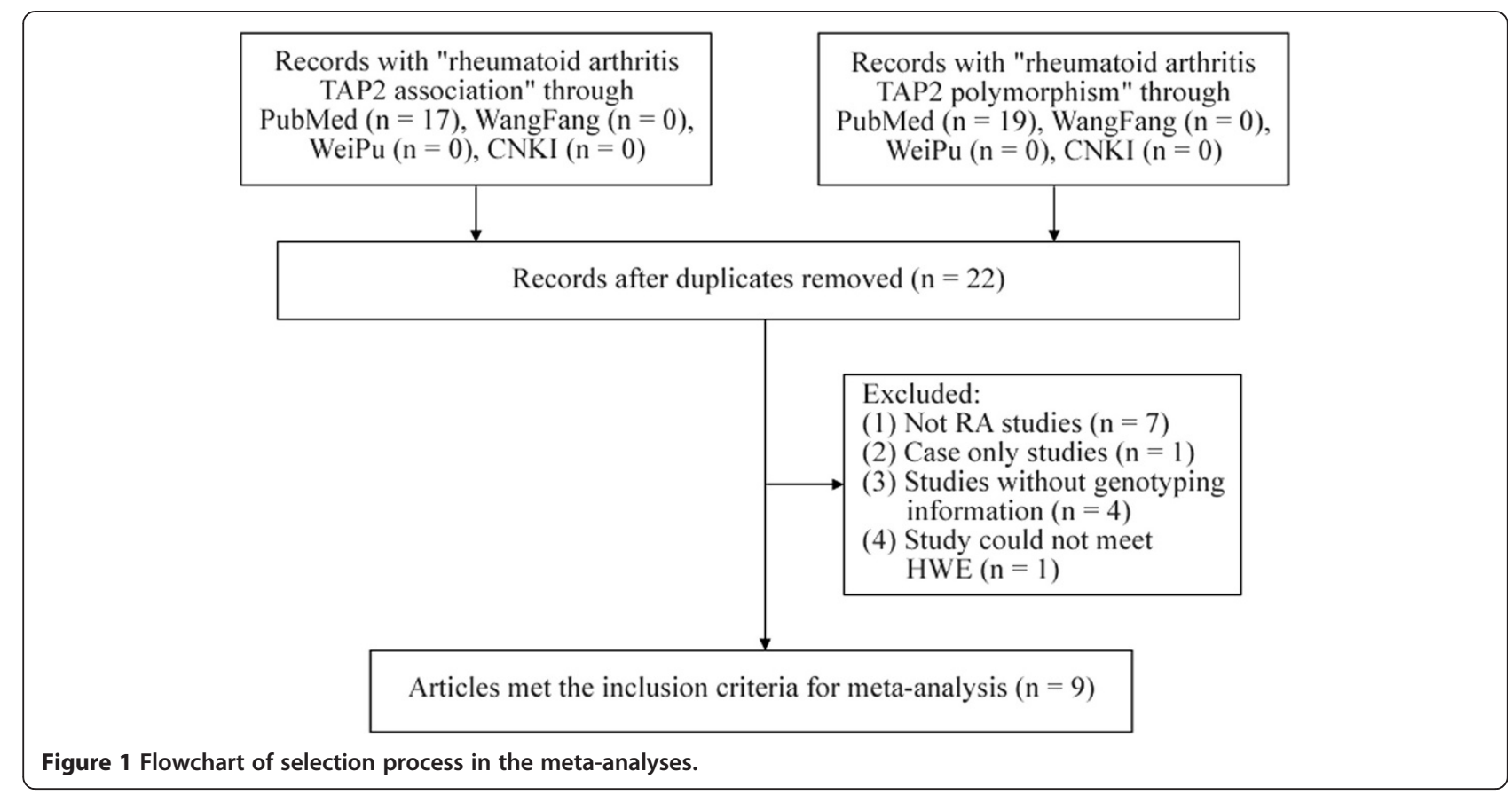

(95\% CIs); (3) Genotype distribution of each polymorphism in controls met Hardy-Weinberg equilibrium (HWE); (4) The cumulative number of individual studies for one genetic locus are at least three. We extracted or calculated the following information from each selected study: the first author, year of publication, country, ethnicity, genotyping method, numbers of cases and controls, control source, HWE for controls, reported association results, power of each involved study and minor allele frequency (MAF) in each stage.

Since some studies presented the data of haplotypes (A to $\mathrm{H}$, Table 2), our study translated the haplotypes into

Table 3 Meta-analyses of TAP2-379, TAP2-565, TAP2-665with RA*

\begin{tabular}{|c|c|c|c|c|c|c|c|}
\hline Genetic locus & Cases/controls (S*) & Genetic model & Ethnicity & OR $(95 \% \mathrm{Cl})$ & $P$ value & $1^{2}$ & Power \\
\hline \multirow[t]{6}{*}{ TAP2-379 } & 796/677 (8) & Overall ( I vs V) & Overall & $1.44(1.18-1.74)$ & 0.0002 & $42 \%$ & 0.477 \\
\hline & $522 / 768(5)$ & & Europeans & $1.39(0.88-2.20)$ & 0.16 & $64 \%$ & 0.286 \\
\hline & 274/293 (3) & & Asians & $1.38(1.04-1.83)$ & 0.03 & $0 \%$ & 0.241 \\
\hline & $320 / 298(3)$ & Dominant ( II/IV vs W ) & & $1.59(1.14-2.22)$ & 0.006 & $0 \%$ & 0.336 \\
\hline & $320 / 298(3)$ & Recessive ( II vs IVM ) & & $1.24(0.58-2.64)$ & 0.58 & $0 \%$ & 0.104 \\
\hline & 198/209 (3) & Additive ( II vs W) & & $1.49(0.68-3.23)$ & 0.32 & $0 \%$ & 0.101 \\
\hline \multirow[t]{6}{*}{ TAP2-565 } & 891/871 (8) & Overall ( T vs A ) & Overall & $1.23(0.84-1.81)$ & 0.28 & $64 \%$ & 0.439 \\
\hline & $522 / 778(5)$ & & Europeans & $1.62(1.20-2.20)$ & 0.002 & $24 \%$ & 0.229 \\
\hline & $369 / 482(3)$ & & Asians & $0.87(0.43-1.75)$ & 0.70 & $76 \%$ & 0.254 \\
\hline & 415/487 (3) & Dominant ( TT/TA vs AA ) & & $1.17(0.85-1.61)$ & 0.33 & $45 \%$ & 0.379 \\
\hline & 415/487 (3) & Recessive ( $T$ vs TA/AA ) & & $4.71(0.51-43.33)$ & 0.17 & $64 \%$ & 0.075 \\
\hline & 335/384 (3) & Additive ( $\Pi$ vs AA ) & & $4.64(0.52-41.77)$ & 0.17 & $64 \%$ & 0.075 \\
\hline \multirow[t]{6}{*}{ TAP2-665 } & $714 / 578(7)$ & Overall ( A vs T) & Overall & $1.02(0.85-1.22)$ & 0.84 & $48 \%$ & 0.557 \\
\hline & $522 / 384(5)$ & & Europeans & $0.87(0.69-1.09)$ & 0.23 & $39 \%$ & 0.475 \\
\hline & 192/194 (2) & & Asians & $1.32(0.99-1.77)$ & 0.06 & $0 \%$ & 0.080 \\
\hline & 238/199 (2) & Dominant ( AA/AT vs TT ) & & $1.07(0.44-2.57)$ & 0.88 & $67 \%$ & 0.252 \\
\hline & 238/199 (2) & Recessive ( AA vs AT/TT ) & & $0.58(0.06-5.77)$ & 0.64 & $77 \%$ & 0.131 \\
\hline & $128 / 100(2)$ & Additive ( $A A$ vs $\Pi$ ) & & $1.15(0.53-2.49)$ & 0.73 & $83 \%$ & 0.122 \\
\hline
\end{tabular}

$S^{*}$ : Amount of stages; V: Valine; I: Isoleucine; A: Alanine; T: Threonine. 
the genotypes of three coding polymorphisms (TAP2-379, TAP2-565, and TAP2-665) $[8,26]$. We used Arlequin program [27] to test whether the genotyping distribution in controls was in HWE. Cochran's Q statistic and $\mathrm{I}^{2}$ test [28] were used to calculate statistical heterogeneity. Fixed-effect model would be used to the studies with minimal to moderate heterogeneity $\left(\mathrm{I}^{2}<50 \%\right)$, and the random-effect model would be used to the studies with significant heterogeneity $\left(\mathrm{I}^{2}>=50 \%\right)$. Combined ORs and CIs were estimated by Review Manager 5 [29]. Funnel plots were drawn to observe the potential publication bias. The power of each study was calculated by Power and Sample Size Calculation program. All the statistical analyses were performed by two independent reviewers (Ping Ru and Xingyu Zhou).

\section{Results and discussion}

As shown in Figure 1, 22 genetic studies on TAP2 gene were initially collected. Of them, we excluded 7 studies that were not related to RA, 1 case-only study, 4 studies without genotyping information, 1 study that did not meet HWE. Finally, 9 articles [14-22] were involved in the current study. Altogether, there were 973 RA patients and 965 controls in the meta-analyses of 3 TAP2 polymorphisms (Tables 1 and 3).

In the present study, we tested the associations between 3 TAP2 polymorphisms and RA disease. Different inheritable models, including dominant, recessive and additive models, were also tested for all 3 polymorphisms. As shown in Table 3 and Figure 2, a significant association of TAP2-379Ile with increased risk of RA was found for combined population $(p=0.0002$, OR $=1.40,95 \%$ $\mathrm{CI}=1.16-1.70$ ). Subgroup analysis by ethnicity showed that this significant association was only found in Asians $(p=0.03, \mathrm{OR}=1.38,95 \% \mathrm{CI}=1.04-1.83$, Table 3 and Figure 2) but not in Europeans $(p=0.16$, Table 3). In addition, significant contribution of TAP2-379Ile to RA was only found in the dominant model $(p=0.006$, OR $=1.59$,
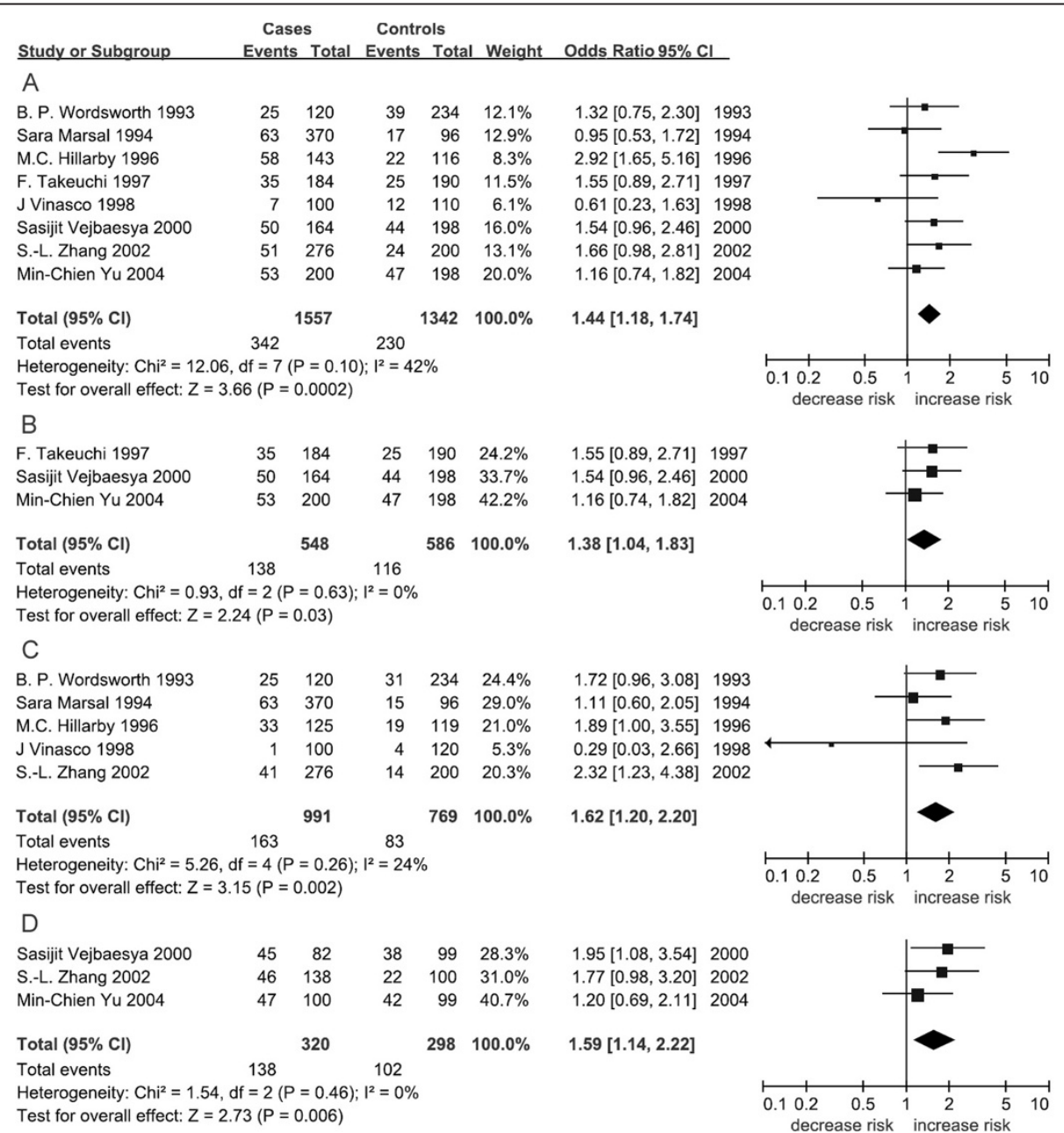

Figure 2 Forest plots of TAP2 gene polymorphisms with RA. A: Forest plot of TAP-379 with RA for combined population; B: Forest plot of TAP-379 with RA in Asians; C: Forest plot of TAP-379 with RA under dominant effect model; D: Forest plot of TAP-565 with RA in Europeans. 
95\% CI = 1.14-2.22, Table 3, Figure 2). For TAP2-565Thr, there was no significant result in the combined populations $(p=0.28$, Table 3$)$, but we found significant association between Europeans and RA $(p=0.002$, OR $=1.62,95 \%$ $\mathrm{CI}=1.20-2.20$, Table 3, Figure 2). For TAP2-665 locus, no significant result was found in the combined meta-analyses or in the subgroup meta-analyses (Table 3).

Significant statistical heterogeneity was found in the meta-analyses of TAP2-565 $\left(\mathrm{I}^{2}=64 \%\right)$. A further subgroup meta-analyses by ethnicity showed that significant heterogeneity was coming from the Europeans for TAP2-379 $\left(\mathrm{I}^{2}=64 \%\right)$ and Asians for TAP2-565 $\left(\mathrm{I}^{2}=76 \%\right)$. Further subgroup studies showed that significant heterogeneity also existed in the meta-analyses of TAP2-565 (recessive model: $\mathrm{I}^{2}=64 \%$; additive model: $\mathrm{I}^{2}=64 \%$ ) and TAP2-665 (dominant model: $\mathrm{I}^{2}=67 \%$, recessive model: $\mathrm{I}^{2}=77 \%$; additive model: $\mathrm{I}^{2}=83 \%$ ).

All the power analyses in current meta-analyses were tested under a moderate risk of SCZ $(\mathrm{OR}=1.2$, Tables 1 and 2). Compared with previous individual studies, our meta-analyses showed a much stronger power (Tables 1 and 3). In addition, no publication bias for the metaanalyses was observed (Figure 3).

To our knowledge, our study was the first meta-analyses of the three coding polymorphisms of TAP2 gene. Previous studies showed significant association between TAP2 gene and autoimmune diseases such as allergic rhinitis [30], systemic lupus erythematosus [31] and RA [20,21]. Our results indicated that TAP2-379Ile was able to increase $44 \%$ of the risk of RA in all subjects and 38\% of the risk of RA in Asians. Moreover, TAP2-379lle was associated with a $59 \%$ increased risk of RA in the dominant model. We also found that TAP2-565Thr increased the risk of RA by $62 \%$ in Europeans.

Previous RA association studies observed a handful of single nucleotide polymorphisms (SNPs) with dominant effect such as $-607 \mathrm{~A} / \mathrm{C}$ polymorphism of $I L-18$ gene [32], rs10489629 of $I L-23 R$ gene [33], -173G/C polymorphism of $M I F$ gene [34] and $-607 \mathrm{~A} / \mathrm{C}$ polymorphism of $I L-18$ gene [32]. Our observation of significant association of TAP2-379Ile polymorphism in the dominant model supported that dominant model might be a key genetic model in the pathogenesis of RA disease.

Since MAFs are different in different populations, we further evaluated the role of TAP2 polymorphisms in Asians and Europeans separately. For TAP2-379Ile, significant association was found in Asians but not in Europeans. On the contrary, we observed TAP2-565Thr as a risky factor of RA in Europeans but not in Asians. This might be due to a lack of power in the subgroup meta-analysis in Europeans for TAP2-379 (power $=0.286$, $\mathrm{I}^{2}=64 \%$ ) and in Asians for TAP2-565 (power $=0.254$, $\left.\mathrm{I}^{2}=76 \%\right)$. To be noted, one Asian study [21] involved in the meta-analyses of TAP2-665Ala was found a high
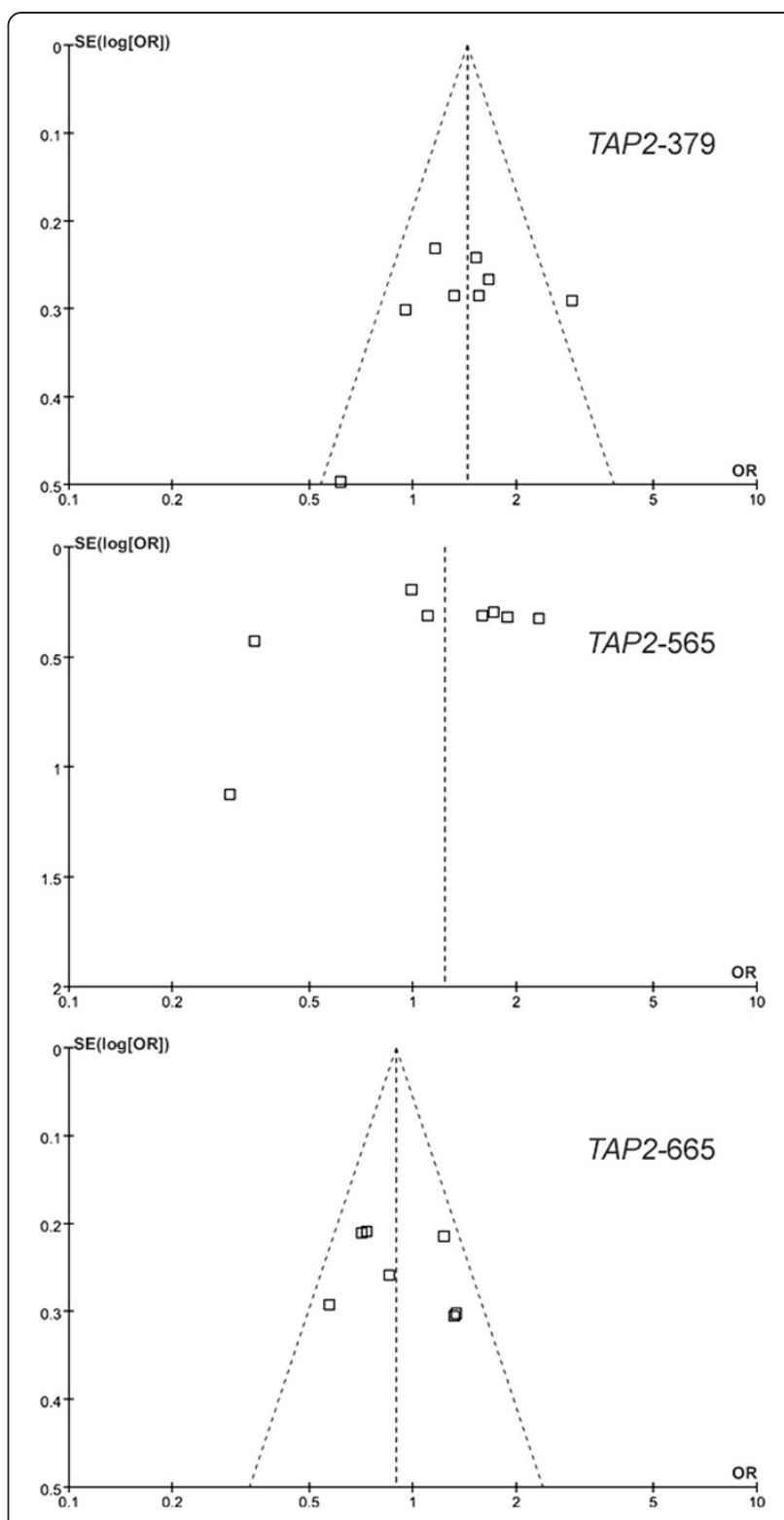

Figure 3 Funnel plots of TAP2 gene polymorphisms with RA.

allele frequency (allele frequency $=0.601$, Table 1 ) than those in the rest studies (average allele frequency $=0.284$ ).

Our meta-analyses presented several limitations that needed to be taken with cautions. Firstly, the associations of TAP2 polymorphisms were only evaluated in Europeans and Asians. The findings might not be feasible for other populations such as Africans. And potential difference in intra-European and intra-Asian population might influence the result of our study (see the MAFs in Table 1). Secondly, $\mathrm{RA}$ is a complex chronic disease. Different clinical variables may influence the results of the current study. Hidden physiological factors may exist in the RA patients and affect the quality of the current meta-analysis. Further studies with precise diagnosis might be helpful for a better meta- 
analysis in the future. Thirdly, although the power of current meta-analyses was much stronger than the previous studies, more replicated studies are required to strengthen the stability of the association between TAP2 polymorphisms and RA. Fourthly, certain multiple testing existed in the current study, and cautions needed to be taken for the significant results. Fifthly, there are 2232 polymorphisms in TAP2 gene according to the NCBI dbSNP database. Our study only focused on three polymorphisms of TAP2 that might be hard to give fully consideration of the contribution of TAP2 polymorphisms. Moreover, the 3 TAP2 polymorphisms might not be the causal variants but be in high linkage disequilibrium with other established RA MHC variants. Sixthly, since significant associations were found in the both allelic and dominant model for TAP2-379, our results implied the genetic models of TAP2-379 polymorphism were complex and hard to be determined. Seventhly, there were publication biases for the current meta-analyses of TAP2-379 and TAP2-565. After removing the outlier studies $[16,17]$, the results of the two meta-analyes remained the same as the previous one.

\section{Conclusions}

In summary, our meta-analyses suggested that TAP2379Ile allele was significantly associated with a 59\% increased risk in the dominant model. To be more specifically, TAP2-379-Ile increased the risk of RA by $38 \%$ in Asians and TAP2-565Thr increased the risk of RA by $38 \%$ in Europeans. Future large-scale and well designed studies are required to confirm our findings and to reveal other TAP2 polymorphisms with contribution to RA disease.

\section{Abbreviations}

RA: Rheumatoid arthritis; SNPs: Single nucleotide polymorphisms; HWE: Hardy-Weinberg equilibriu; ORs: Odds ratios; 95\% Cls: 95\% confidence intervals.

\section{Competing interests}

None of the authors have any commercial or other association that might pose a conflict of interest. All authors are responsible for the content and writing of the paper.

\section{Authors' contributions}

SD participated in research design. YC, PR, XZ, YH and LX selected the articles, $Q H$, LT, GP, DL, QG and YL performed data analysis. The manuscript was drafted by $\mathrm{DD}, \mathrm{YC}$ and SD, and critically reviewed and discussed with the other co-authors. All the authors read and approved the final manuscript.

\section{Authors' information}

Dongjun Dai and Yong Chen: Co-first authors of this work.

\begin{abstract}
Acknowledgements
The research was supported by the grants from National Natural Science Foundation of China (31100919 and 81371469), Natural Science Foundation of Zhejiang Province (LR13H020003), K. C. Wong Magna Fund in Ningbo University, and Ningbo Social Development Research Projects (2012C50032).
\end{abstract}

\section{Author details}

'Zhejiang Provincial Key Laboratory of Pathophysiology, School of Medicine, Ningbo University, Ningbo, Zhejiang 315211, China. ${ }^{2}$ Department of Rheumatology, Ningbo No.2 Hospital, Ningbo, Zhejiang 315010, China.
Received: 21 March 2014 Accepted: 23 June 2014

Published: 27 June 2014

\section{References}

1. Bossaller $\mathrm{L}$, Rothe $\mathrm{A}$ : Monoclonal antibody treatments for rheumatoid arthritis. Expert Opin Biol Ther 2013, 13:1257-1272.

2. Chen J, Liu W, Lin Q, Chen L, Yin J, Huang H: Vitamin D deficiency and low bone mineral density in native Chinese rheumatoid arthritis patients. Int $\mathrm{J}$ Rheum Dis 2013, 17:66-70.

3. Koivuniemi R, Paimela L, Suomalainen R, Leirisalo-Repo M: Cardiovascular diseases in patients with rheumatoid arthritis. Scand J Rheumatol 2013, 42:131-135.

4. MacGregor AJ, Snieder H, Rigby AS, Koskenvuo M, Kaprio J, Aho K, Silman AJ: Characterizing the quantitative genetic contribution to rheumatoid arthritis using data from twins. Arthritis Rheum 2000, 43:30-37.

5. Wordsworth P, Bell J: Polygenic susceptibility in rheumatoid arthritis. Ann Rheum Dis 1991, 50:343-346.

6. Choi SJ, Rho YH, Ji JD, Song GG, Lee YH: Genome scan meta-analysis of rheumatoid arthritis. Rheumatology (Oxford) 2006, 45:166-170.

7. Ollier W, Thomson W: Population genetics of rheumatoid arthritis. Rheum Dis Clin N Am 1992, 18:741-759.

8. Powis SH, Tonks S, Mockridge I, Kelly AP, Bodmer JG, Trowsdale J: Alleles and haplotypes of the MHC-encoded ABC transporters TAP1 and TAP2. Immunogenetics 1993, 37:373-380.

9. Robertson M: Antigen processing. Proteasomes in the pathway. Nature 1991, 353:300-301.

10. Momburg F, Roelse J, Hammerling GJ, Neefjes JJ: Peptide size selection by the major histocompatibility complex-encoded peptide transporter. J Exp Med 1994, 179:1613-1623.

11. Bauer D, Tampe R: Herpes viral proteins blocking the transporter associated with antigen processing TAP-from genes to function and structure. Curr Top Microbiol Immunol 2002, 269:87-99.

12. Yang HC, Liang YJ, Chung CM, Chen JW, Pan WH: Genome-wide gene-based association study. BMC Proc 2009, 3(7):S135.

13. Lee HS, Lee AT, Criswell LA, Seldin MF, Amos Cl, Carulli JP, Navarrete C, Remmers EF, Kastner DL, Plenge RM, Li W, Gregersen PK: Several regions in the major histocompatibility complex confer risk for anti-CCP-antibody positive rheumatoid arthritis, independent of the DRB1 locus. Mol Med 2008, 14:293-300

14. Wordsworth BP, Pile KD, Gibson K, Burney RO, Mockridge I, Powis SH: Analysis of the MHC-encoded transporters TAP1 and TAP2 in rheumatoid arthritis: linkage with DR4 accounts for the association with a minor TAP2 allele. Tissue Antigens 1993, 42:153-155.

15. Marsal S, Hall MA, Panayi GS, Lanchbury JS: Association of TAP2 polymorphism with rheumatoid arthritis is secondary to allelic association with HLA-DRB1. Arthritis Rheum 1994, 37:504-513.

16. Hillarby MC, Davies EJ, Donn RP, Grennan DM, Ollier WE: TAP2D is associated with HLA-B44 and DR4 and may contribute to rheumatoid arthritis and Felty's syndrome susceptibility. Clin Exp Rheumatol 1996, 14:67-70.

17. Takeuchi F, Nakano K, Matsuta K, Takizawa K, Nabeta H, Kuwata S, Ito K: Polymorphism of TAP1 and TAP2 in Japanese patients with rheumatoid arthritis. Tissue Antigens 1997, 49:280-282.

18. Vinasco J, Fraile A, Nieto A, Beraun Y, Pareja E, Mataran L, Martin J: Analysis of LMP and TAP polymorphisms by polymerase chain reaction-restriction fragment length polymorphism in rheumatoid arthritis. Ann Rheum Dis 1998, 57:33-37.

19. Vejbaesya S, Luangtrakool P, Luangtrakool K, Sermduangprateep C, Parivisutt L: Analysis of TAP and HLA-DM polymorphism in thai rheumatoid arthritis. Hum Immunol 2000, 61:309-313.

20. Zhang SL, Chabod J, Penfornis A, Reviron D, Tiberghien P, Wendling D, Toussirot E: TAP1 and TAP2 gene polymorphism in rheumatoid arthritis in a population in eastern France. Eur J Immunogenet 2002, 29:241-249.

21. Yu MC, Huang CM, Wu MC, Wu JY, Tsai FJ: Association of TAP2 gene polymorphisms in Chinese patients with rheumatoid arthritis. Clin Rheumatol 2004, 23:35-39.

22. Yu L, Li Q, Lin J, Yu J, Yi W, Sun H, Chu JY, Yang ZQ, Yu L, Li Q, Lin J, Yu J, Yi W, Sun H, Chu JY, Yang ZQ: Association between polymorphisms of PSMB8, PSMB9 and TAP2 genes with rheumatoid arthritis in ethnic Han Chinese from Yunnan. Zhonghua Yi Xue Yi Chuan Xue Za Zhi 2013, 30:222-226.

23. Tuokko J, Pushnova E, Yli-Kerttula U, Toivanen A, llonen J: TAP2 alleles in inflammatory arthritis. Scand J Rheumatol 1998, 27:225-229. 
24. Button KS, loannidis JP, Mokrysz C, Nosek BA, Flint J, Robinson ES, Munafo MR: Power failure: why small sample size undermines the reliability of neuroscience. Nat Rev Neurosci 2013, 14:365-376.

25. Tao JH, Zou YF, Feng XL, Li J, Wang F, Pan FM, Ye DQ: Meta-analysis of TYK2 gene polymorphisms association with susceptibility to autoimmune and inflammatory diseases. Mol Biol Rep 2011, 38:4663-4672.

26. Jackson DG, Capra JD: TAP2 association with insulin-dependent diabetes mellitus is secondary to HLA-DQB1. Hum Immunol 1995, 43:57-65.

27. Excoffier L, Laval G, Schneider S: Arlequin (version 3.0): an integrated software package for population genetics data analysis. Evol Bioinformatics Online 2005, 1:47-50.

28. Coory MD: Comment on: Heterogeneity in meta-analysis should be expected and appropriately quantified. Int J Epidemiol 2010, 39:932.

29. Kawalec P, Mikrut A, Wisniewska N, Pilc A: The effectiveness of tofacitinib, a novel Janus kinase inhibitor, in the treatment of rheumatoid arthritis: a systematic review and meta-analysis. Clin Rheumatol 2013, 32:1415-1424.

30. Kim KR, Cho SH, Choi SJ, Jeong JH, Lee SH, Park CW, Tae K: TAP1 and TAP2 gene polymorphisms in Korean patients with allergic rhinitis. J Korean Med Sci 2007, 22:825-831.

31. Correa PA, Molina JF, Pinto LF, Arcos-Burgos M, Herrera M, Anaya JM: TAP1 and TAP2 polymorphisms analysis in northwestern Colombian patients with systemic lupus erythematosus. Ann Rheum Dis 2003, 62:363-365.

32. Chen S, Jiang F, Ren J, Liu J, Meng W: Association of IL-18 polymorphisms with rheumatoid arthritis and systemic lupus erythematosus in Asian populations: a meta-analysis. BMC Med Genet 2012, 13:107.

33. Song GG, Bae SC, Choi SJ, Ji JD, Lee YH: Associations between interleukin-23 receptor polymorphisms and susceptibility to rheumatoid arthritis: a meta-analysis. Mol Biol Rep 2012, 39:10655-10663.

34. Xie Q, Wang SC, Bian G, Zhan FL, Xie JK, Li J: Association of MIF-173G/C and MBL2 codon 54 gene polymorphisms with rheumatoid arthritis: a meta-analysis. Hum Immunol 2012, 73:966-971.

doi:10.1186/1746-1596-9-129

Cite this article as: Dai et al:: Significant association between TAP2 polymorphisms and rheumatoid arthritis: a meta-analysis. Diagnostic Pathology 2014 9:129.

\section{Submit your next manuscript to BioMed Central and take full advantage of:}

- Convenient online submission

- Thorough peer review

- No space constraints or color figure charges

- Immediate publication on acceptance

- Inclusion in PubMed, CAS, Scopus and Google Scholar

- Research which is freely available for redistribution 